\title{
LOCALIZATION OF SUBSTANCE P-LIKE AND ENKEPHALIN-LIKE IMMUNOREACTIVITY WITHIN PREGANGLIONIC TERMINALS OF THE AVIAN CILIARY GANGLION: LIGHT AND ELECTRON MICROSCOPY ${ }^{1}$
}

\author{
JONATHAN T. ERICHSEN, ${ }^{2}$ HARVEY J. KARTEN, WILLIAM D. ELDRED, AND \\ NICHOLAS C. BRECHA ${ }^{3}$
}

Departments of Psychiatry and Behavioral Sciences and Neurobiology and Behavior, State University of New York at Stony Brook, Stony Brook, New York 11794

Received September 1, 1981; Revised February 23, 1982; Accepted February 26, 1982

\begin{abstract}
The avian ciliary ganglion receives its only recognized input from the nucleus of Edinger-Westphal. This is known to be a cholinergic input. In the present study, using fluorescein isothiocyanate and peroxidase-antiperoxidase immunohistochemical methods, substance P-like and enkephalin-like immunoreactivity has been found within preganglionic terminals of the avian ciliary ganglion. The ciliary ganglion is known to consist of two distinct cell populations: small choroid cells that project to the smooth muscle coat of the choroid and large ciliary neurons that send axons to both the iris and the ciliary body. Preganglionic terminals on choroid cells consist of small boutonal endings, whereas ciliary neurons receive a calyx-like cap ending around the hilus of the cell. Substance P-like and enkephalin-like immunoreactivity was localized to preganglionic axons and to both boutonal and calyx-like terminations upon cells of the ciliary ganglion.

Electron microscopic studies of both substance P-like and enkephalin-like immunoreactive terminals revealed small clear core vesicles $(\sim 58 \mathrm{~nm}$ in diameter) and two sizes of dense core vesicles ( $\sim 85$ and $\sim 119 \mathrm{~nm}$ in diameter). Immunoreactive staining was observed only in the smaller dense core vesicles. The unlabeled clear core vesicles were clustered at synaptic release sites, while the immunoreactive and larger unlabeled dense core vesicles usually were not near these synaptic specializations. These observations strongly imply that neuropeptides co-occur with acetylcholine in preganglionic axons of the ciliary ganglion.
\end{abstract}

The ciliary ganglion is a parasympathetic ganglion which receives its only known input from the nucleus of Edinger-Westphal (Cowan and Wenger, 1968; Narayanan and Narayanan, 1976; Lyman and Mugnaini, 1980). The organization of the avian ciliary ganglion has been studied extensively with anatomical, physiological, biochemical, and developmental methods (Martin and Pilar, 1963a, b; Landmesser and Pilar, 1970, 1972, 1974, 1978; Cantino and Mugnaini, 1975; Varon et al., 1979; Adler et

\footnotetext{
' This work was supported by United States Public Health Service Grants EY07039 (to J. T. E.), EY02146 (to H. J. K.), and EY03801 (to W. D. E.). We wish to thank Christine Laverack and Brian Davis for technical assistance. We gratefully acknowledge the help of Dr. Anton Reiner, who read the manuscript and offered many helpful suggestions.

'To whom correspondence should be addressed at Department of Psychiatry and Behavioral Sciences, State University of New York at Stony Brook, Stony Brook, NY 11794.

Present address: Center for Ulcer Research and Education, Veterans Administration-Wadsworth, Los Angeles, CA 90073.
}

al., 1979; Pilar et al., 1980). The ciliary ganglion consists of two distinct cell populations, choroid and ciliary, which can be differentiated anatomically as well as physiologically (Hess, 1965; Marwitt et al., 1971; Cantino and Mugnaini, 1975). The choroid cells are small $(25-\mu \mathrm{m}$ diameter) unmyelinated neurons whose axons pass out through the choroid nerve and terminate in the smooth muscle coat of the choroid (Landmesser and Pilar, 1970). In contrast, ciliary neurons of the ganglion have large (45- $\mu$ m-diameter) myelinated somata and send their axons via the ciliary nerves to both the iris and the ciliary body. In birds, the iris musculature is striated (Pilar and Vaughan, 1969). The postsynaptic receptors of the choroid neuron terminals in the smooth muscle of the choroidal vasculature are muscarinic (Landmesser and Pilar, 1970); those of the ciliary neuron terminals in the iris and ciliary body are nicotinic (Pilar and Vaughan, 1969).

There are corresponding presynaptic differences between the preganglionic axons terminating upon the choroid and ciliary neurons of the avian ciliary ganglion. 
Choroid cells are innervated by small diameter, slow conducting axons which terminate in small bouton synapses indented in the cell soma (Landmesser and Pilar, 1970, 1972). Only chemical transmission occurs across this synapse. The transmitter is acetylcholine, and the postsynaptic receptors of the ganglionic cell bodies are nicotinic (Landmesser and Pilar, 1970). Ciliary cells, on the other hand, are innervated by large, fast conducting axons which terminate in calyces in the newly hatched bird. These calyciform endings occur at the hilar pole where the postganglionic axon emerges and cover approximately 25 to $50 \%$ of the cell surface. Later in development, this calyx breaks up into many large contiguous boutons that, in light microscopic examination, still appear as a solid cap over one end of the cell (Landmesser and Pilar, 1972; Cantino and Mugnaini, 1975). Synaptic transmission in this cap-like terminal ending on ciliary neurons is both chemical (nicotinic cholinergic) and electrical (Martin and Pilar, 1963a; Hess et al., 1969). We will refer to this terminal ending as a cap.

There are about 6200 neurons in the ciliary ganglion of the pigeon (Terzuolo, 1951; Pilar and Tuttle, 1982). About $60 \%$ of these are choroid cells, and the other $40 \%$ are ciliary neurons (Johnson and Pilar, 1980). There are no known interneurons present in the ganglion (Terzuolo, 1951). Each postganglionic ciliary cell is innervated by only one preganglionic fiber (Cantino and Mugnaini, 1975); each postganglionic choroid cell is innervated by fibers from as many as 3 preganglionic neurons (Pilar and Tuttle, 1982).

The present study reports our findings on the presence of substance P-like and enkephalin-like immunoreactivity in both classes of preganglionic axonal terminals of the ciliary ganglion. Electron microscopic analysis of these immunoreactive terminals has demonstrated dense core vesicles associated with both substance P-like and enkephalin-like immunoreactivity in addition to smaller unlabeled clear core synaptic vesicles clustered at apparent synaptic release sites.

\section{Materials and Methods}

Light microscopy methods. Adult white Carneaux pigeons were used. All animals were anesthetized deeply and perfused via the heart with $6 \%$ dextran in $0.1 \mathrm{M}$ phosphate buffer (PB), pH 7.4, followed by PLP fixative, PB containing $4 \%(\mathrm{w} / \mathrm{v})$ paraformaldehyde, $0.1 \mathrm{M}$ lysine $\mathrm{HCl}$, and $0.01 \mathrm{~m}$ sodium periodate (McLean and Nakane 1974). The ciliary ganglia were either dissected free of the surrounding tissue or left in situ, fixed for an additional 2 to $3 \mathrm{hr}$ in the same fixative at $4^{\circ} \mathrm{C}$, and then transferred to a fresh solution of 20 to $30 \%$ sucrose buffer and stored at $4^{\circ} \mathrm{C}$. Serial sections were cut at $10 \mu \mathrm{m}$ using a cryostat and collected onto gelatin-coated slides. Sections then were washed three times in $\mathrm{PB}$ at room temperature for a total of $30 \mathrm{~min}$ and processed for immunohistochemical staining. Prior to washing, sections could be stored at $-20^{\circ} \mathrm{C}$.

Sections were incubated either in monoclonal substance P (SP) antibody raised in tissue culture from rat spleen hybridoma (Accurate Chemical and Scientific Corp.; Cuello et al., 1979) at a dilution of 1:1000 or in antiserum to $\mathrm{Leu}^{5}$-enkephalin (ENK) raised in rabbit (courtesy of Dr. K. -J. Chang, Burroughs-Wellcome) at a dilution of 1:2000. Both antibodies were diluted in PB with $0.3 \%$ Triton $\mathrm{X}-100$. After incubating in the antibody for 12 to $56 \mathrm{hr}$ at $4^{\circ} \mathrm{C}$, the sections were washed three times in PB for a total of $30 \mathrm{~min}$ and processed according to the indirect fluorescent method of Coons (1958) or the peroxidase-antiperoxidase (PAP) method of Sternberger (1979).

For the indirect fluorescent method, the sections reacted with SP antibody were incubated in goat anti-rat IgG conjugated to fluorescein isothiocyanate (FITC; Miles Biochemicals) at a 1:50 dilution, whereas the sections reacted with ENK antiserum were incubated in goat anti-rabbit IgG conjugated to FITC (Miles Biochemicals) at a 1:100 dilution. Both IgGs were diluted in PB with $0.3 \%$ Triton X-100. Sections were incubated for $45 \mathrm{~min}$ at room temperature, washed three times in PB for a total of $30 \mathrm{~min}$, and then coverslipped with a solution of glycerol, $0.05 \mathrm{M}$ carbonate buffer $(9: 1$ by volume), $\mathrm{pH}$ 9.5. For the $\mathrm{PAP}$ method, the sections reacted with SP antibody were incubated in goat anti-rat IgG (Miles Biochemicals) at a dilution of $1: 50$, and the sections reacted with ENK antiserum were incubated with goat anti-rabbit IgG (Miles Biochemicals) at a dilution of 1:100. Following an incubation of $45 \mathrm{~min}$, the sections were washed in three changes of $\mathrm{PB}$ over a period of $30 \mathrm{~min}$ and then placed in rat (SternbergerMeyer) or rabbit (Dako) peroxidase-antiperoxidase (PAP) at a 1:50 dilution for $45 \mathrm{~min}$ at room temperature. After a 30-min PB wash, sections were placed in a solution of $3,3^{\prime}$-diaminobenzidine tetrahydrochloride (DAB) $(1 \mathrm{mg} / \mathrm{ml})$ in $0.1 \mathrm{M}$ cacodylate, $0.1 \mathrm{M}$ imidazole buffer $(\mathrm{pH}$ 7.0) for a 20 -min preincubation, followed by an additional incubation for $10 \mathrm{~min}$ after the addition of hydrogen peroxide (to yield a final concentration of $0.01 \% \mathrm{H}_{2} \mathrm{O}_{2}$ ). Following the $\mathrm{DAB}$ incubation, the reaction product was intensified by incubating the sections with $0.1 \%$ osmium tetroxide $\left(\mathrm{OsO}_{4}\right)$ in $\mathrm{PB}$ for $1 \mathrm{~min}$. After a final buffer wash, the sections were cleared and coverslipped with Permount. The specificity of the immunoreactive SP-like and ENK-like staining was tested by incubating adjacent sections from each ciliary ganglion at a dilution of 1:1000 (SP) or 1:2000 (ENK) in the primary antibody preadsorbed with $10 \mu \mathrm{M}$ synthetic substance P (SP; Boehringer Mannheim) or $4 \mu \mathrm{M}$ synthetic Leu ${ }^{5}$-enkephalin (ENK; Boehringer Mannheim), respectively.

Because of the difficulty of establishing the precise antigenic determinant of an immunohistochemical stain (Vandesande, 1979), we use the terms "SP-like immunoreactivity" and "ENK-like immunoreactivity" to describe the staining in the ciliary ganglion. The terms "SPpositive" or "ENK-containing" are used throughout this paper for synonyms for SP-like or ENK-like immunoreactivity. We have attempted to establish the specificity of the immunoreaction by the absence of positive staining of the terminal endings when the primary antibodies are preadsorbed with the corresponding synthetic peptide (i.e., SP or ENK). However, the success of these "blocked" control experiments does not exclude the possibility that the immunoreactive materials present in the terminal endings of the ciliary ganglion are related structurally, but not identical, to SP or ENK.

FITC-conjugated fluorescent stained sections were ex- 
amined with a Leitz microscope with Ploem epi-illumination. PAP-reacted sections were studied with Leitz differential interference contrast optics as well as with bright-field light microscopy.

One ciliary ganglion from an adult pigeon was sectioned serially on a cryostat, and each section $(10 \mu \mathrm{m})$ was collected onto a separate gelatin-coated slide. One series, consisting of every fourth section through the entire ganglion, was reacted for SP and an alternate series of every fourth section was reacted for ENK, in both cases using the PAP procedure. The SP series of slides was counterstained lightly with toluidine blue to allow the visualization of all cell bodies in each section. Using bright-field light microscopy, all sections from both the SP and ENK series were examined and counts were made of neurons receiving labeled cap-like endings and neurons receiving labeled beaded boutonal endings. In order to estimate the total number of neurons repre- sented in the complete series of sections through the ganglion, all neurons were counted in each section of the counterstained SP series. The type of neuron (choroid or ciliary) receiving unlabeled terminal endings could not be determined reliably.

Electron microscopy methods. Three white Carneaux pigeons were perfused with $6 \%$ dextran followed by a modified PLP fixative with $2.5 \%$ paraformaldehyde. The six ciliary ganglia were dissected free of the orbit and postfixed for 2 to $3 \mathrm{hr}$ in the same fixative at $4^{\circ} \mathrm{C}$. The ganglia then were sectioned into PB at $50 \mu \mathrm{m}$ using a Vibratome and washed for $1 \mathrm{hr}$ in PB. The sections were incubated in SP or ENK antibody and processed according to the PAP procedure described above with the omission of Triton X-100 from all solutions. The sections then were fixed for $1 \mathrm{hr}$ with $1 \% \mathrm{OsO}_{4}$ in $\mathrm{PB}$, dehydrated in graded acetones, and embedded in Epon resin. The 50$\mu \mathrm{m}$ sections were examined in the light microscope to
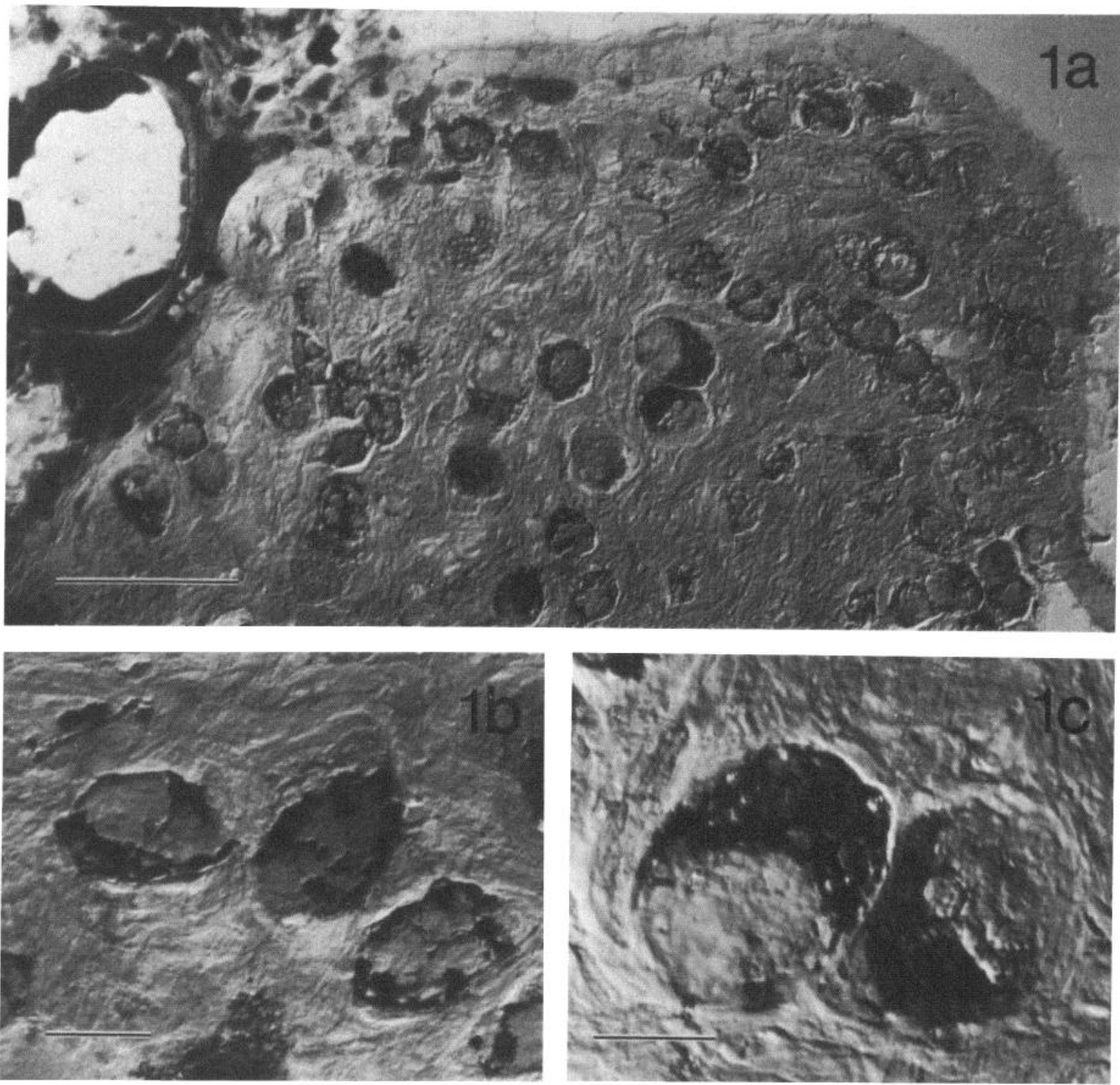

Figure 1. Substance P-like immunoreactivity in preganglionic terminal endings of the pigeon ciliary ganglion as demonstrated using the PAP technique. A $10-\mu \mathrm{m}$ section through the ciliary ganglion at low magnification $(a)$ reveals substance P-like immunoreactivity throughout the ganglion in both boutonal and cap-like terminal endings. Scale bar, $100 \mu \mathrm{m}$. Immunoreactive boutonal endings on choroid neurons $(b)$ and cap-like endings on ciliary neurons $(c)$ are shown at higher magnification. Scale bar, $20 \mu \mathrm{m}$. The photomicrographs were taken using Leitz differential interference optics. 
locate labeled terminals. Thin sections (silver-gold range) then were cut with a diamond knife and examined unstained with a JEOL $100 \mathrm{C}$ electron microscope. Blocked control sections were treated exactly as above but with the addition of $10 \mu \mathrm{M}$ synthetic SP or $4 \mu \mathrm{M}$ synthetic ENK to the corresponding primary antibody $24 \mathrm{hr}$ prior to the incubation of the tissue. Size measurements were made using an ocular micrometer $(\times 10)$ to examine the original negatives. For each vesicle type, an average diameter was calculated.

\section{Results}

\section{Light microscopy results}

The pattern of immunoreactive staining in the ciliary ganglion was virtually identical for both SP and ENK. Sections of the ciliary ganglia stained with antibody against SP or ENK characteristically demonstrated intense staining of the presynaptic terminal endings on cells of the ganglion (Figs. $1 a$ and $2 a$ ). Some of the labeled endings formed an apparently continuous cap around the hilus of the cell, with darker punctate immunoreactive loci occasionally visible within the cap (Figs. $1 c$ and $2 b$ ). In some cases, individual labeled fibers with beaded boutonal endings extended beyond the cap toward the nonhilar pole of the cell. The cell postsynaptic to this cap-like ending is reported to be a ciliary neuron (Hess, 1965; Marwitt et al., 1971). The other type of labeled terminal ending consisted of intensely labeled fibers with coarse beaded boutonal profiles scattered over all parts of the neuronal cell body (Figs. $1 b$ and $2 c$ ). The cells which receive these boutonal terminal endings are choroid neurons (Hess, 1965; Marwitt et al., 1971).

In all sections examined for SP-like or ENK-like im-
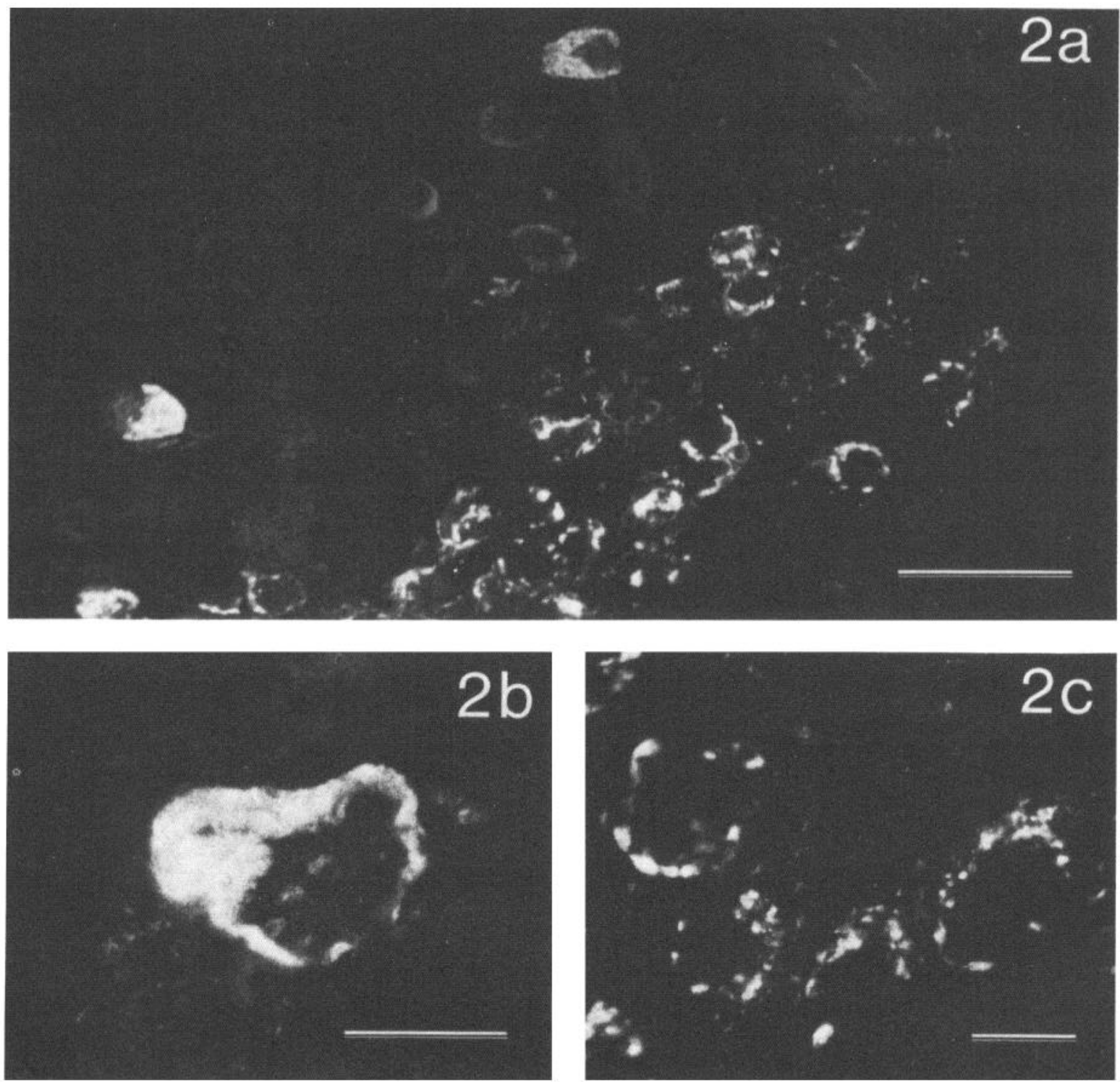

Figure 2. Enkephalin-like immunoreactivity in preganglionic terminal endings of the pigeon ciliary ganglion as demonstrated using the FITC method. A $10-\mu \mathrm{m}$ section through the ciliary ganglion at low magnification $(a)$ reveals enkephalin-like immunoreactivity throughout the ganglion in both boutonal and cap-like terminal endings. Scale bar, $100 \mu \mathrm{m}$. The patterns of immunoreactive staining for substance $\mathrm{P}$ and enkephalin are remarkably similar (see Fig. 1). Immunoreactive cap-like endings on ciliary neurons $(b)$ and boutonal endings on choroid neurons $(c)$ are shown at higher magnification. Scale bar, $20 \mu \mathrm{m}$. The photomicrographs were taken with a Leitz microscope with Ploem epi-illumination. 
TABLE I

Proportion of ciliary ganglion neurons receiving immunoreactive terminal endings

\begin{tabular}{|c|c|c|c|c|c|c|c|}
\hline \multirow{3}{*}{ Antibody } & \multirow{3}{*}{ Total Number of Cells } & \multicolumn{2}{|c|}{ Estimated Number of Cells" } & \multicolumn{4}{|c|}{ Number and Proportion ${ }^{h}$ of Cells Receiving Labeled Terminals } \\
\hline & & \multirow{2}{*}{ Ciliary } & \multirow{2}{*}{ Choroid } & \multicolumn{2}{|c|}{ Ciliary } & \multicolumn{2}{|c|}{ Choroid } \\
\hline & & & & Number & Percent & Number & Percent \\
\hline $\mathrm{SP}$ & 1742 & 697 & 1045 & 369 & 53 & 562 & 54 \\
\hline ENK & $1452^{c}$ & 581 & 871 & 225 & 39 & 514 & 59 \\
\hline
\end{tabular}

"Based on the reported relative proportions of ciliary (40\%) and choroid (60\%) neurons in the adult pigeon ciliary ganglion (Johnson and Pilar, 1980).

${ }^{h}$ Percentages were calculated as a proportion of the estimated number of ciliary and choroid cells in the entire series of sections through the ganglion.

Estimated from the total number of cells counted in the SP series of sections and adjusted for the exclusion of two damaged sections in the ENK series.

munoreactivity, a large proportion of the neurons received labeled caps or beaded boutonal endings. A variable fraction ( 37 to $57 \%$ ) of postganglionic cells, however, were not associated with immunoreactive presynaptic endings. Counts made of the labeled caps and boutonal endings through an entire ganglion revealed that about the same relative proportions of ciliary and choroid neurons received SP-like and ENK-like immunoreactive endings (see Table I). Moreover, the ratios of labeled boutonal endings to labeled caps in both SP-reacted (1.52) and ENK-reacted (2.28) tissue were similar to the reported ratio of the total number of choroid to ciliary neurons in the ganglion (1.5; Johnson and Pilar, 1980). The total number of neurons in the counterstained SP series of sections through the ganglion was approximately 1740. Using the reported ratio of the total number of choroid to ciliary cells in the pigeon ciliary ganglion (i.e., 1.5; Johnson and Pilar, 1980), we calculated the approximate respective proportions of all choroid and ciliary cells receiving labeled presynaptic endings (see Table I). These proportions were similar in tissue reacted for SP and ENK. On average, approximately $57 \%$ of choroid cells and $46 \%$ of ciliary cells received labeled presynaptic endings.

There was no clear-cut positive staining of cell bodies, although scattered cells were found to demonstrate very faint background staining. Reacting sections with "blocked" antibodies eliminated all staining of both kinds of terminal endings, but no diminution of the faint background staining of cell bodies was observed. We thus conclude that there is no evidence for the presence of intrinsic SP- or ENK-containing neurons in the ciliary ganglion.

\section{Electron microscopy results}

Substance $P$. When SP-labeled synaptic boutons on choroid neurons were examined at low magnification, the entire bouton had increased electron density and was quite easily distinguished from unlabeled boutons. These labeled terminals were covered and separated from each other by processes of the glial cells which surrounded the nerve cell body. Some labeled boutons invaginated several micrometers into the cell body of the postsynaptic neuron. We have not been able to determine if all of the labeled boutons on an individual choroid neuron were from a single presynaptic axon or from several different presynaptic axons (see Martin and Pilar, 1963a; Terzuolo,
1951; Cantino and Mugnaini, 1975; Pilar and Tuttle, 1982).

The individual SP-positive synaptic boutons, measured in randomly selected thin sections, were approximately 2 by 3 to $4 \mu \mathrm{m}$ in size (Fig. 3). Examination at higher magnification revealed that a large proportion of the area of contact between an SP-positive synaptic bouton and the postsynaptic neuron showed specialized membrane organization and presynaptic clusters of small clear core vesicles, suggesting transmitter release sites. In these regions of contact, the postsynaptic specializations consisted of a relatively uniform electron-dense material adherent to the cytoplasmic face of the postsynaptic membrane.

The labeled synaptic boutons were crowded with cellular organelles. A large portion of the bouton was packed densely with numerous small ( $57 \pm 2 \mathrm{~nm} \mathrm{SE;} N=12$ ) clear core synaptic vesicles and many elongated mitochondria $(0.15 \times 1 \mu \mathrm{m})$ with longitudinally oriented cristae. An electron-dense coating was seen surrounding the external membranes of cellular organelles, including the mitochondria, while the mitochondrial matrix remained free of reaction product. Larger vesicles $(84 \pm 3 \mathrm{~nm} \mathrm{SE}$; $N=10$ ) with electron-dense contents also were found in these boutons. The clear and distinctive labeling of the contents of the large dense core vesicles strongly suggests that they do contain SP-like immunoreactivity. Notably, only the smaller clear core synaptic vesicles were clustered near the synaptic membrane specializations, while the larger dense core vesicles often were found associated with clusters of mitochondria some distance from the presumed synaptic release sites. In some labeled boutons, there were occasional unlabeled dense core vesicles which were significantly larger than the labeled dense core vesicles $(120 \pm 6 \mathrm{~nm}$ SE; $N=8)$. Both the labeled dense core and the larger unlabeled dense core vesicles were found in the same locations within the synaptic boutons.

The mean sizes of the labeled and unlabeled dense core vesicles were significantly different $(t=5.67 ; d f=16 ; p$ $<0.001$ ), suggesting that there are, in fact, two different kinds of dense core vesicles in the presynaptic terminal endings of the ciliary ganglion. However, the actual size distributions of labeled and unlabeled dense core vesicles overlap (i.e., some unlabeled dense core vesicles were indistinguishable from labeled dense core vesicles in terms of their size alone). These smaller unlabeled dense 

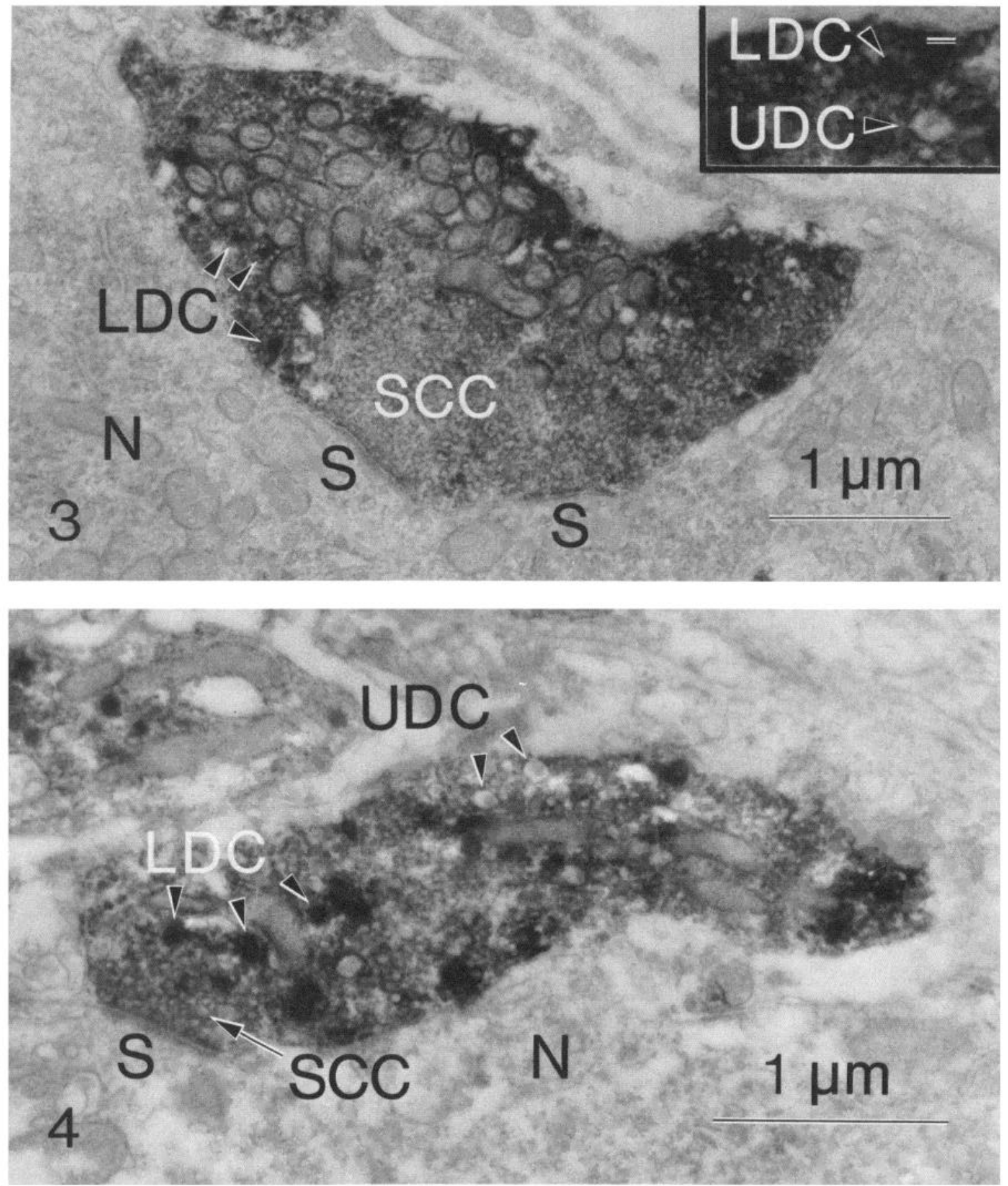

Figures 3 and 4. Electron micrographs of synaptic boutons with substance P-like (Fig. 3) and enkephalin-like (Fig. 4) immunoreactivity contacting choroid neurons $(N)$. An electron-dense cytoplasmic reaction product surrounds the external membranes of the organelles within the boutons. Labeled dense core vesicles $(L D C)$ contain dense reaction product, while the unlabeled dense core vesicles $(U D C)$ and the small clear core vesicles $(S C C)$ do not. Only small clear core vesicles are clustered at the synaptic specializations $(S)$. The sections are not stained with heavy metals. The inset in Figure 3 shows both a $U D C$ and a $L D C$ from a different bouton at higher magnification. Scale bar, $100 \mathrm{~nm}$.

core vesicles might contain other substances or simply may be larger dense core vesicles in another plane of section. In all labeled boutons examined, very few of the smaller dense core vesicles were unlabeled.

Synaptic terminal endings on ciliary neurons consisted of numerous large boutons which abutted each other to form a continuous cap over the hilar pole of the soma (see also Cantino and Mugnaini, 1975). These SP-positive caps had ultrastructural characteristics similar to the SPpositive boutons, small labeled dense core vesicles, some larger unlabeled dense core vesicles, numerous smaller unlabeled clear core vesicles, and synaptic release sites with the small unlabeled clear core vesicles clustered nearby.

Enkephalin. ENK-like immunoreactivity, as in the SP immunohistochemistry discussed above, was found in 
both synaptic boutons on choroid neurons and caps on ciliary neurons. Ultrastructural examination of beaded boutonal terminal endings revealed the same three types of synaptic vesicles found in SP-like immunoreactive boutons (Fig. 4). Numerous small unlabeled clear core vesicles ( $59 \pm 1 \mathrm{~nm} \mathrm{SE} ; N=24)$ were clustered around synaptic release sites, while dense core vesicles were distributed away from such specializations. Dense core vesicles containing immunoreactive material were consistently smaller (86 $\pm 3 \mathrm{~nm} \mathrm{SE;} N=21$ ) than unlabeled dense core vesicles (118 $\pm 3 \mathrm{~nm} \mathrm{SE} ; N=20 ; t=2.79 ; d f$ $=39 ; p<0.01)$. These large unlabeled dense core vesicles were much more abundant in ENK-positive boutons than in SP-positive boutons. Electron-dense reaction product coated the external membranes of cellular organelles as well as mitochondria, and the synaptic membrane specializations resembled those found in SP-positive boutons.

ENK-like immunoreactive caps were also similar in most respects to SP-containing endings on ciliary neurons (Fig. 5). Electron-dense reaction product was localized to the contents of small dense core vesicles as well as to the external membrane surface of the cytoplasmic organelles within the presynaptic terminal. In some lightly stained ENK-containing caps, however, some diffuse cytoplasmic reaction product occurred in patches rather than evenly throughout the presynaptic terminal. In addition, some amorphous clusters of electron-dense reaction product were found in the cytoplasm of cells postsynaptic to immunoreactive endings. These amorphous clusters were associated with smooth endoplasmic reticulum and mitochondria (Fig. 5).

\section{Discussion}

Light microscopy. Prominent SP-like and ENK-like immunoreactivity has been found in both boutonal and calyx-like terminal endings within the avian ciliary ganglion. These two distinct kinds of preganglionic synapses are reported to innervate the choroid and ciliary neurons, respectively (Hess, 1965; Marwitt et al., 1971). The ciliary ganglion is a ganglion of the cranial component of the parasympathetic nervous system. Although we were unable to find any previous reports of the presence of substance $P$ in the ciliary ganglion or in any other parasympathetic system, Glazer and Basbaum (1980) recently localized enkephalin-like immunoreactivity within sacral spinal cord and parasympathetic preganglionic neurons. The only identified source of afferents to the ciliary ganglion are those axons originating in the nucleus of Edinger-Westphal (EW) (Lyman and Mugnaini, 1980). EW has been found to contain SP- and ENK-positive cells, which have been shown with lesion experiments to be the source of the SP- and ENK-containing terminal endings reported in the present study (Erichsen et al., 1981). Although EW is known to consist of distinct dorsolateral and ventromedial subdivisions (Cowan and Wenger, 1968; Narayanan and Narayanan, 1976), the differential projection of each of these subdivisions upon the dual population of cells in the ciliary ganglion is unknown. SP- and ENK-positive cells are found in both subdivisions of EW (Erichsen et al., 1981).

In tissue reacted for either SP or ENK, well over half of the choroid neurons in the serially sectioned ganglion received both SP- and ENK-positive boutonal endings. Moreover, the relative proportions of choroid and ciliary cells receiving immunoreactive endings were similar for SP- and ENK-reacted tissue. These results strongly suggest that at least some of the presynaptic terminals might contain both SP and ENK; that is that the two neuropeptides co-occur in boutons and/or caps of the ciliary ganglion. Using a double label technique that allows simultaneous visualization of SP-like and ENK-like immunoreactivity in the same section at the light microscopic level, we have confirmed in a separate study that the two neuropeptides, SP and ENK (or structurally similar compounds), co-occur in the same terminal endings within the ciliary ganglion as well as in the same preganglionic neurons of EW (Erichsen et al., 1982).

Electron microscopy. Previous ultrastructural immunohistochemical studies of peptidergic nerve endings indicate that peptides usually are present in large "granular," or dense core, vesicles (see review in Hökfelt et al., 1980a). Ultrastructural examination of SP- and ENK-immunoreactive beaded boutonal endings in the ciliary ganglion revealed two distinct size classes of dense core vesicles $(\sim 85$ and $\sim 119 \mathrm{~nm}$ in diameter). When reacted for SP or ENK, only the smaller dense core vesicles were immunoreactive, while the larger vesicles consistently were unlabeled. The same general pattern also was found in immunoreactive caps with one difference: larger unlabeled dense core vesicles were comparatively rare. Although not all smaller dense core vesicles were labeled in some terminal endings, very few were unlabeled when reacted for either SP or ENK. In view of the light microscopic evidence for the co-occurrence of SP and ENK in the same terminal endings of the ganglion (Erichsen et al., 1982), the comparative rarity of unlabeled smaller dense core vesicles is consistent with the possibility that SP and ENK actually may be contained in the same vesicles. Of course, only terminal endings which were labeled densely with SP or ENK were selected for thin sectioning. More lightly labeled endings may have revealed a larger proportion of unlabeled small dense core vesicles. Further experiments are needed to identify the contents of the larger unlabeled dense core vesicles.

Both kinds of dense core vesicles consistently were located away from the synaptic release sites, whereas the clear core vesicles normally were clustered near these synaptic membrane specializations. Serial reconstructions were not done in the present ultrastructural studies, however; therefore, it remains possible that immunoreactive dense core vesicles may be released at some as yet unobserved synaptic release sites. In addition, it is possible that there is nonsynaptic release of these peptidergic dense core vesicles, as proposed for certain aminergic neurotransmitters (see review in Dismukes, 1979). Philippe and Tremblay (1981) report a marked reduction of dense core vesicles in the cap endings of the ciliary ganglion following in vivo stimulation of $\mathrm{EW}$ in the chick, and they suggest that these dense core vesicles may play an active role in synaptic transmission.

Although electron-dense reaction product was seen on the external membranes of organelles (including clear core vesicles and mitochondria) within the presynaptic 
boutons and caps, this does not necessarily indicate the presence of immunoreactivity or the existence of a cytoplasmic pool of SP and/or ENK within the terminal. Diffusion of the DAB reaction product away from the antigenic sites (e.g., the small labeled dense core vesicles) might account for the cytoplasmic label surrounding the membranous components of the presynaptic terminal. Moreover, the significance of postsynaptic electron-dense reaction product seen in ENK-reacted tissue, but not in material reacted for SP, remains unclear. Because there were no labeled endings in blocked antibody controls, it was impossible to determine which postsynaptic neurons should be examined for the amorphous clusters of electron-dense reaction product found in neurons postsynaptic to ENK-positive endings.

Synaptic transmission in the ciliary ganglion. The ciliary ganglion has been considered to be exclusively cholinergic in both its preganglionic and postganglionic

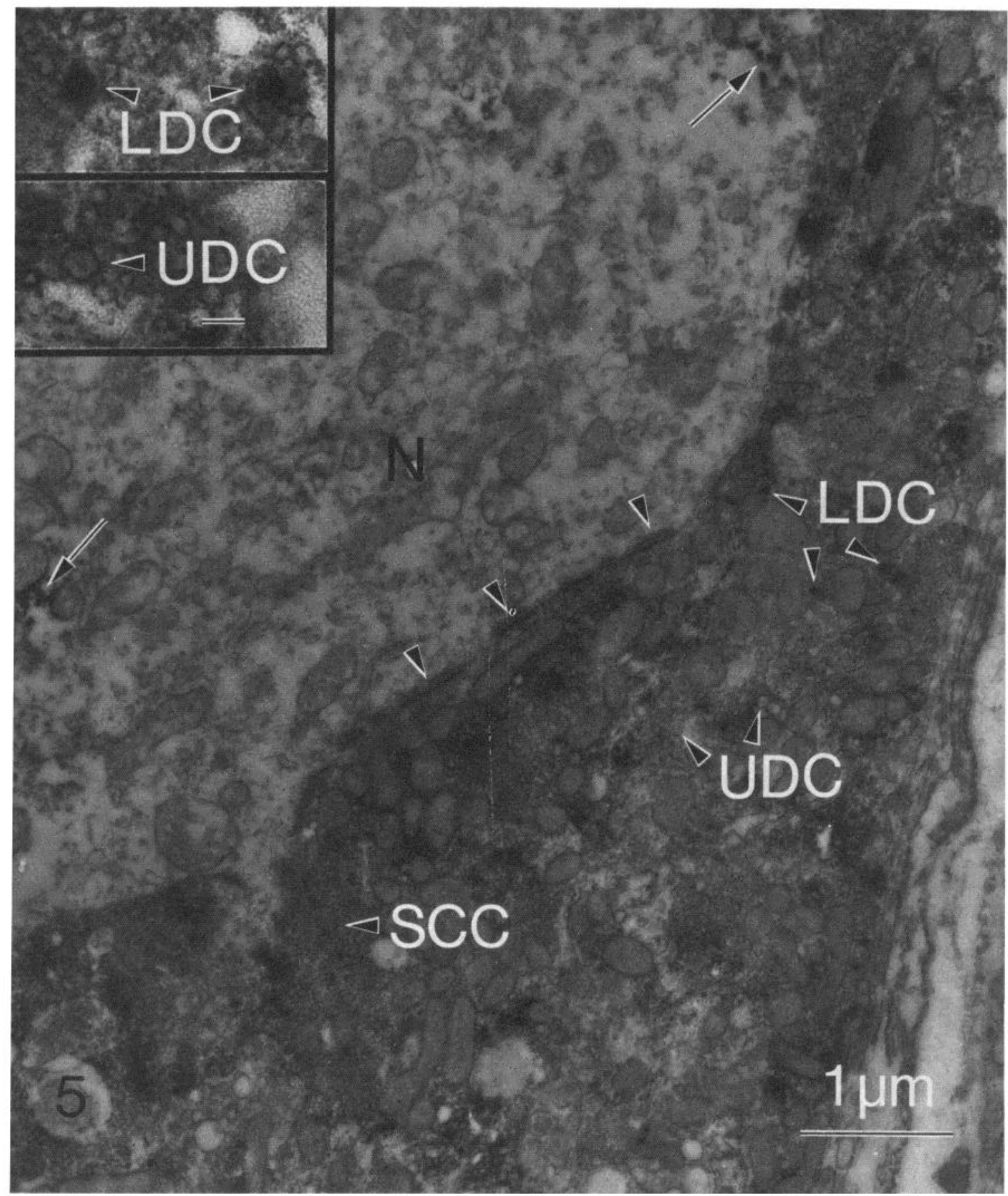

Figure 5. Electron micrograph of a cap-like cluster of boutons with enkephalin-like immunoreactivity contacting a ciliary neuron $(N)$. Immunoreactivity can be seen within labeled dense core vesicles $(L D C)$ and in several patches within the postsynaptic neuron (arrows). The large unlabeled dense core vesicles $(U D C)$ and the small clear core vesicles $(S C C)$ are free of reaction product. Only the small clear core vesicles are found at the synaptic specializations (arrowheads). The section is not stained with heavy metals. The insets show two $L D C s$ (top) and a $U D C$ (bottom) from a different cap ending at higher magnification. Scale bar, $100 \mathrm{~nm}$. 
components (e.g., Martin and Pilar, 1963a, b; Marwitt et al., 1971; Pilar et al., 1973; Burt and Narayanan, 1976; Giacobini et al., 1979). Although a small population of adrenergic fibers has been reported to innervate choroid cells in the chick ciliary ganglion (Ehinger, 1967; Cantino and Mugnaini, 1974), no true synaptic relationships involving adrenergic varicosities and choroid cells have yet been demonstrated. The afferent cholinergic axons to the ciliary ganglion originate in EW (Cowan and Wenger, 1968; Narayanan and Narayanan, 1976; Lyman and Mugnaini, 1980). Unilateral lesions of $\mathrm{EW}$ in the pigeon have demonstrated that the SP-containing and enkephalinergic terminal endings described in this study arise from neurons in the ipsilateral EW (Erichsen et al., 1981). These two results raise the distinct possibility that SP and ENK coexist with acetylcholine in the preganglionic terminal endings of the ciliary ganglion.

Acetylcholine is known to be a transmitter within the preganglionic endings of the ciliary ganglion, and the clustering of the unlabeled clear core vesicles near synaptic release sites is consistent with the suggestion that the clear core vesicles may contain acetylcholine (Whittaker and Zimmerman, 1974; Kelly et al., 1979). However, we are unable at this time to demonstrate the co-occurrence of acetylcholine (ACh) with either SP or ENK. The Baughman and Bater (1977) method for ACh autoradiography may be of use, but its value in the present instance is limited since the postganglionic cells of the ciliary ganglion synthesize ACh (Johnson and Pilar, 1980). In light of the high concentration of $\mathrm{ACh}$ in the postganglionic neurons (Pilar et al., 1973), autoradiography probably could not provide sufficient resolution to determine whether a given presynaptic terminal ending also contains $\mathrm{ACh}$. The fact that SP-like and ENK-like immunoreactivity is contained in vesicles raises the possibility that these neuropeptides also may be released (see Iversen et al., 1980; Hökfelt et al., 1980b). Although the peptide-containing dense core vesicles were not found at synaptic specializations, they may have been dispersed from their normal location by the action of the fixatives or released elsewhere along the presynaptic membrane (Dismukes, 1979). In view of the likely presence of $\mathrm{ACh}$ in the same endings, SP and ENK may play a role as neuromodulators rather than as the primary transmitters in this system (see Hökfelt et al., 1978; Lundberg et al., 1979).

As noted above, not all terminal endings in the ciliary ganglion are labeled with either SP or ENK when examined separately for each peptide. Therefore, we cannot rule out the possibility that the peptidergic terminal endings within the ciliary ganglion represent a subpopulation of preganglionic axons which are distinct from the cholinergic fibers innervating the ganglion. On the other hand, the fact that a large proportion of the preganglionic terminals are labeled with SP or ENK strongly suggests that there is at least some co-occurrence of ACh with SP and ENK. The present results indicate that neuropeptides play some as yet undefined role in the parasympathetic pathway controlling the pupillary reflex and accommodation.

The mechanism of action of opiates on the pupil remains obscure (Davson, 1980). Perhaps the meiotic effect in some vertebrates is mediated by direct action of opi- ates on the ciliary ganglion. The means of interaction of $\mathrm{ENK}$ and $\mathrm{ACh}$ to potentiate the presumably meiotic role of $\mathrm{ACh}$, however, appears paradoxical in light of the reported "inhibitory" actions of ENK on postsynaptic membranes (Ziegelgansberger and Tulloch, 1979). Ciliary ganglion neurons provide a fruitful model for the analysis of the various postulated roles of the peptides: the effect of ENK or SP on the binding of $\alpha$-bungarotoxin to the nicotinic receptor sites (Nishi and Berg, 1979), their effects on phosphorylation in the ciliary ganglionic neurons, their role in the differentiation of ciliary neurons, and their involvement in the regulation of $\mathrm{ACh}$ synthesis.

\section{References}

Adler, R., K. Landa, M. Manthorpe, and S. Varon (1979) Cholinergic neuronotrophic factors: II. Intraocular distribution of trophic activity for ciliary neurons. Science 204: 14341436.

Baughman, R. W., and C. R. Bader (1977) Biochemical characterization and cellular localization of the cholinergic system in the chicken retina. Brain Res. 138: 469-485.

Burt, A. M., and C. H. Narayanan (1976) Choline acetyltransferase, choline kinase, and acetylcholinesterase activities during development of the chick ciliary ganglion. Exp. Neurol. 53: 703-713.

Cantino, D., and E. Mugnaini (1974) Adrenergic innervation of the parasympathetic ciliary ganglion in the chick. Science 185: $279-281$.

Cantino, D., and E. Mugnaini (1975) The structural basis for electronic coupling in the avian ciliary ganglion. A study with thin sectioning and freeze-fracturing. J. Neurocytol. 4: 505536.

Coons, A. H. (1958) Fluorescent antibody methods. In General Cytochemical Methods, J. F. Danielli, ed., pp. 399-422, Academic Press, New York.

Cowan, W. M., and E. Wenger (1968) Degeneration in the nucleus of origin of the preganglionic fibers to the chick ciliary ganglion following early removal of the optic vesicle. J. Exp. Zool. 168: 105-124.

Cuello, A. C., G. Galfre, and C. Milstein (1979) Detection of substance $\mathrm{P}$ in the central nervous system by a monoclonal antibody. Proc. Natl. Acad. Sci. U. S. A. 76: 3532-3536.

Davson, H. (1980) Physiology of the Eye, Ed. 4, pp. 468-477, Churchill Livingstone, New York.

Dismukes, R. K. (1979) New concepts of molecular communication among neurons. Behav. Brain Sci. 2: 409-448.

Ehinger, B. (1967) Adrenergic nerves in the avian eye and ciliary ganglion. Z. Zellforsch. Mikrosk. Anat. 82: 577-588.

Erichsen, J. T., A. Reiner, J. Cabot, and H. J. Karten (1981) Neurons of the nucleus of Edinger-Westphal are the source of enkephalinergic and substance $\mathbf{P}$-containing terminals in the avian ciliary ganglion. Soc. Neurosci. Abstr. 7: 777.

Erichsen, J. T., A. Reiner, and H. J. Karten (1982) Co-occurrence of substance P-like and Leu-enkephalin-like immunoreactivities in neurones and fibres of avian nervous system. Nature 295: 407-410.

Giacobini, E., G. Pilar, J. Suszkiw, and H. Uchimura (1979) Normal distribution and denervation changes of neurotransmitter related enzymes in cholinergic neurones. J. Physiol (Lond.) 286: 233-253.

Glazer, E. J., and A. I. Basbaum (1980) Leucine enkephalin: Localization in and axoplasmic transport by sacral parasympathetic preganglionic neurons. Science 208: 1479-1480.

Hess, A. (1965) Developmental changes in the structure of the synapse on the myelinated cell bodies of the chicken ciliary ganglion. J. Cell Biol. 25: 1-19. 
Hess, A., G. Pilar, and J. N. Weakly (1969) Correlation between transmission and structure in avian ciliary ganglion synapses. J. Physiol. (Lond.) 202: 339-354.

Hökfelt, T., A. Ljungdahl, H. Steinbusch, A. Verhofstad, G. Nilsson, E. Brodin, B. Pernow, and M. Goldstein (1978) Immunohistochemical evidence of substance P-like immunoreactivity in some 5-hydroxytryptamine-containing neurons in the rat central nervous system. Neuroscience 3: 517538.

Hökfelt, T., O. Johansson, A. Ljungdahl, J. M. Lundberg, and M. Schultzberg (1980a) Peptidergic neurons. Nature 284: 515-521.

Hökfelt, T., J. M. Lundberg, M. Schultzberg, O. Johansson, A. Ljungdahl, and J. Rehfeld (1980b) Coexistence of peptides and putative transmitters in neurons. In Neural Peptides and Neuronal Communication, E. Costa and M. Trabucchi, eds., pp. 1-23, Raven Press, New York.

Iversen, L. I., C. M. Lee, R. F. Gilbert, S. Hunt, and P. C. Emson (1980) Regulation of neuropeptide release. Proc. R. Soc. Lond. (Biol.) 210: 91-111.

Johnson, D. A., and G. Pilar (1980) The release of acetylcholine from post-ganglionic cell bodies in response to depolarization. J. Physiol. (Lond.) 299: 605-619.

Kelly, R. B., J. W. Deutsch, S. S. Carlson, and J. A. Wenger (1979) Biochemistry of neurotransmitter release. Annu. Rev. Neurosci. 2: 399-446.

Landmesser, L., and G. Pilar (1970) Selective reinnervation of two cell populations in the adult pigeon ciliary ganglion. $J$. Physiol. (Lond.) 211: 203-216.

Landmesser, L., and G. Pilar (1972) The onset and development of transmission in the chick ciliary ganglion. J. Physiol. (Lond.) 222: 691-713.

Landmesser, L., and G. Pilar (1974) Synaptic transmission and cell death during normal ganglionic development. J. Physiol. (Lond.) 241: 737-749.

Landmesser, L., and G. Pilar (1978) Interactions between neurons and their targets during in vivo synaptogenesis. Fed. Proc. 37: 2016-2022.

Lundberg, J. M., T. Hökfelt, M. Schultzberg, K. Uvnas-Wallensten, C. Kohler, and S. I. Said (1979) Occurrence of vasoactive intestinal polypeptide (VIP)-like immunoreactivity in certain cholinergic neurons of the cat: Evidence from combined immunohistochemistry and acetyl-cholinesterase staining. Neuroscience 4: 1539-1559.

Lyman, D., and E. Mugnaini (1980) The avian accessory oculomotor nucleus. Soc. Neurosci. Abstr. 6: 479.

Martin, A. R., and G. Pilar (1963a) Dual mode of synaptic transmission in the avian ciliary ganglion. J. Physiol. (Lond.) 168: 443-463.
Martin, A. R., and G. Pilar (1963b) Transmission through the ciliary ganglion of the chick. J. Physiol. (Lond.) 168: 464-475.

Marwitt, R., G. Pilar, and J. N. Weakly (1971) Characterization of two ganglion cell populations in avian ciliary ganglia. Brain Res. 25: 317-334.

McLean, I. W., and P. K. Nakane (1974) Periodate-lysine-paraformaldehyde fixative: A new fixative for immunoelectron microscopy. J. Histochem. Cytochem. 22: 1077-1083.

Narayanan, C. H., and Y. Narayanan (1976) An experimental inquiry into the central source of preganglionic fibers to the chick ciliary ganglion. J. Comp. Neurol. 166: 101-110.

Nishi, R., and D. K. Berg (1979) Survival and development of ciliary ganglion neurones grown alone in cell culture. Nature 277: 232-234.

Philippe, E., and J. P. Tremblay (1981) In vivo stimulation of a cholinergic synapse of the chick ciliary ganglion induces a reduction in the number of dense core vesicles. Neurosci. Lett. 24: 307-312.

Pilar, G., and J. B. Tuttle (1982) A simple neuronal system with a range of uses: The avian ciliary ganglion. In Model Cholinergic Synapses, Raven Press, New York, in press.

Pilar, G., and P. C. Vaughan (1969) Electrophysiological investigations of the pigeon iris neuromuscular junctions. Comp. Biochem. Physiol. 29: 51-72.

Pilar, G., D. J. Jenden, and B. Campbell (1973) Distribution of acetylcholine in the normal and denervated pigeon ciliary ganglion. Brain Res. 49: 245-256.

Pilar, G., L. Landmesser, and L. Burstein (1980) Competition for survival among developing ciliary ganglion cells. J. Neurophysiol. 43: 233-254.

Sternberger, L. A. (1979) Immunocytochemistry, Ed. 2, John Wiley and Sons, New York.

Terzuolo, C. A. (1951) Richerche sul ganglio ciliare degli Uccelli. Connessioni e mutamenti in relazione all'eta' e dopo recisione delle fibre pregangliari. Z. Zellforsch. Mikrosk. Anat. 36: 255267.

Vandesande, F. (1979) A critical review of immunocytochemical methods for light microscopy. J. Neurosci. Methods. 1: 3-23.

Varon, S., M. Manthorpe, and R. Adler (1979) Cholinergic neuronotrophic factors: I. Survival, neurite outgrowth and choline acetyltransferase in monolayer cultures from chick embryo ciliary ganglia. Brain Res. 173: 29-45.

Whittaker, V. P., and H. Zimmerman (1974) Biochemical studies on cholinergic synaptic vesicles. In Synaptic Transmission and Neuronal Interactions, M. V. L. Benn, ed., pp. 217238, Raven Press, New York.

Ziegelgansberger, W., and I. Tulloch (1979) The effects of methionine- and leucine-enkephalin on spinal neurons of the cat. Brain Res. 167: 53-64. 